\title{
What is the importance of solitary focal bony FDG-uptake on 18F-FDG PET-CT of known cancer patients?
}

\author{
LI Sonoda*, A Lakhani, S Ghosh-Ray \\ From International Cancer Imaging Society (ICIS) 14th Annual Teaching Course \\ Heidelberg, Germany. 9-11 October 2014
}

\begin{abstract}
Aim
18F-FDG-PET-CT plays an important role in oncology staging. While the presence of multiple FDG-avid lesions on PET-CT in the context of known malignancy is generally considered metastases, the exact significance of solitary FDG-avid-lesions remains unknown. This study was undertaken to evaluate the significance of solitary bony lesions on PET-CT of oncology patients.
\end{abstract}

\section{Methods}

Retrospective review of 15,645 PET-CT studies was performed. Further evaluation of solitary bony FDG-avid lesions was carried out by conventional imaging, follow-up and biopsy studies. Spontaneous resolution on subsequent PET-CT without a change in therapy was considered benign while progression was considered malignant.

\section{Results}

361 (3\%) cases were found to have single FDG-avid skeletal lesions, of which 16 were due to uptake at the primary bony malignancy, and 42 were not further-investigated/ passed away, hence excluded. Of the remaining 303 lesions 276 (91\%) were confirmed as metastases, 27 (9\%) proven benign ( 10 by imaging, 5 by biopsy and 12 by follow-up).

Of 276 metastases (SUVmax 9.6+/-6.6); 191 were lytic, 45 sclerotic, 21 mixed and 19 normal on CT. Of 27 benign (SUVmax 3.8+/-2.8); 2 were lytic, 7 sclerotic, 2 mixed and 16 normal on CT. PPV of PET-CT on lytic, sclerotic, mixed and normal lesions on CT are 99\%, 87\%, 91\% and $54 \%$ respectively. There was significant difference in SUVmax between malignant/benign lesions $(\mathrm{P}<0.001)$.

* Correspondence: luke@sonoda.co.uk

Paul Strickland Scanner Centre, Mount Vernon Hospital, London, UK

PET-CT correctly upstaged in $83 / 303$ (27\%) cases, but incorrectly upstaged or suggested further investigation in $18 / 303(6 \%)$ cases.

\section{Conclusion}

Solitary skeletal FDG-uptake on 18F-FDG-PET-CT in patients with known malignancy is just as significant as multiple skeletal FDG-uptake, carrying high risk of metastases.

Published: 9 October 2014

doi:10.1186/1470-7330-14-S1-P6

Cite this article as: Sonoda et al:: What is the importance of solitary focal bony FDG-uptake on 18F-FDG PET-CT of known cancer patients? Cancer Imaging 2014 14(Suppl 1):P6.
Submit your next manuscript to BioMed Central and take full advantage of:

- Convenient online submission

- Thorough peer review

- No space constraints or color figure charges

- Immediate publication on acceptance

- Inclusion in PubMed, CAS, Scopus and Google Scholar

- Research which is freely available for redistribution
() Biomed Central 